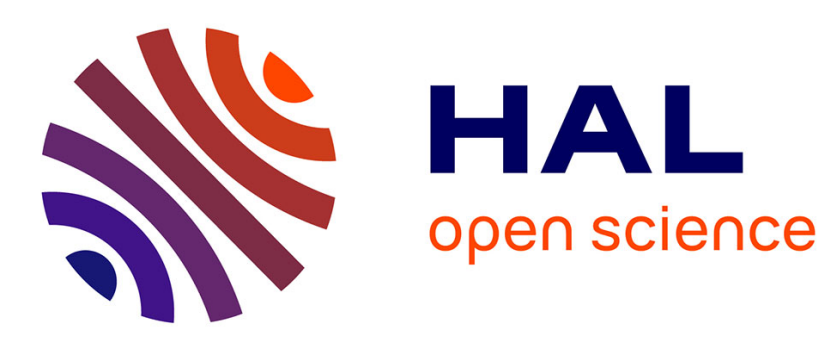

\title{
Trophic selectivity in aquatic isopods increases with the availability of resources
}

\author{
Clémentine François, Laurent Simon, Florian Malard, Tristan Lefébure, \\ Christophe Jean Douady, Florian Mermillod-Blondin
}

\section{To cite this version:}

Clémentine François, Laurent Simon, Florian Malard, Tristan Lefébure, Christophe Jean Douady, et al.. Trophic selectivity in aquatic isopods increases with the availability of resources. Functional Ecology, 2020, 34, pp.1078-1090. 10.1111/1365-2435.13530 . hal-02492518

\section{HAL Id: hal-02492518 https://univ-lyon1.hal.science/hal-02492518}

Submitted on 10 Dec 2020

HAL is a multi-disciplinary open access archive for the deposit and dissemination of scientific research documents, whether they are published or not. The documents may come from teaching and research institutions in France or abroad, or from public or private research centers.
L'archive ouverte pluridisciplinaire HAL, est destinée au dépôt et à la diffusion de documents scientifiques de niveau recherche, publiés ou non, émanant des établissements d'enseignement et de recherche français ou étrangers, des laboratoires publics ou privés. 
11 Clémentine M. Francois ${ }^{\mathrm{a}^{*}}$, Laurent Simon ${ }^{\mathrm{a}}$, Florian Malard ${ }^{\mathrm{a}}$, Tristan Lefébure ${ }^{\mathrm{a}}$,

12 Christophe J. Douady ${ }^{\mathrm{a}, \mathrm{b}}$ and Florian Mermillod-Blondin ${ }^{\mathrm{a}}$

14 a Univ Lyon, Université Claude Bernard Lyon 1, CNRS, ENTPE, UMR5023 LEHNA, F-69622,

15 Villeurbanne, France

16 b Institut Universitaire de France, Paris, France

$17 *$ Corresponding author: clementine.francois@univ-lyon1.fr

22 Keywords

$23 \mathrm{C}$ and $\mathrm{N}$ stable isotopes - diet determination - freshwater isopods - resource availability - resource

24 diversity - selective feeding - stoichiometric quality - trophic choices 


\section{ABSTRACT}

26 1. Trophic selectivity has major influences on consumers' fitness, stability of predator and prey

27 populations, and nutrient fluxes in food webs. Trophic selectivity occurs when the relative

28 abundances of resources in a consumer's diet differ from their relative abundances in the

29 environment. This discrepancy between resources abundance and use has been predicted to

30 increase with the availability of resources in the environment. Trophic selectivity has also been

31 predicted to increase with the heterogeneity of resources quality in the environment. Despite their

32 ecological and evolutionary implications, conclusive in situ tests of these predictions are still

33 lacking.

34 2. We challenged these two predictions by studying 15 closely related species of isopods

35 distributed along a wide range of resource availability (from 1.3 to 57.6 grams of organic carbon

36 per square meter). The dataset ranged from deep cave systems, considered as some of the most

37 resource-limited environments on Earth, to highly-productive surface streams.

38 3. For each species, we quantified the relative abundance of all available resources in the

39 environment and estimated the heterogeneity in the stoichiometric quality of these resources.

40 Isopod diet was determined using $\mathrm{C}$ and $\mathrm{N}$ stable isotopes and a Bayesian mixing model. The

41 degree of trophic selectivity was then calculated for each species.

42 4. By coupling a standardized quantification of trophic resources with a fine determination of

43 diets using stable isotopes, we uncovered a positive relationship between resource availability and

44 trophic selectivity. Contrary to our second prediction, trophic selectivity did not correlate with the

45 heterogeneity of resources quality.

46 5. Our results have important implications in trophic ecology by highlighting that resource

47 availability was a main driver of trophic choices in aquatic invertebrates across a broad range of

48 environments. These findings call for further evaluation of the mechanisms (e.g. trophic 49 competition) causing the positive relationship between trophic selectivity and resource 
50 availability, as these mechanisms could be closely linked to those generating the documented

51 relationship between species richness and productive energy.

\section{INTRODUCTION}

56 Trophic selectivity has been recognized to have profound consequences for consumers' fitness

57 (Cruz-Rivera \& Hay, 2000; McMurray et al., 2016), for the stability of grazer and prey 58 populations (Strom \& Loukos, 1998; Meunier et al., 2016), and for nutrient fluxes and recycling 59 in food webs (Marcarelli et al., 2011; Hood et al., 2014). Trophic selectivity occurs when the 60 relative abundances of resource types in a consumer's diet differ from their relative abundances in 61 the environment (Chesson, 1978). Therefore, selective feeders are consumers discriminating

62 among the available resources in the environment by selecting specific resources (i.e. resources

63 which are more represented in consumer's diet than in the environment; Feinsinger et al.; 1981;

64 Peterson \& Ausubel, 1984).

66 The degree of trophic selectivity in organisms has been predicted to vary with the availability of 67 resources in the environment (e.g. Anthony \& Kunz, 1977; Tinker et al., 2008; Correa \& 68 Winemiller, 2014). According to the predictions of the optimal foraging theory (OFT; 69 Roughgarden, 1972; Pyke et al., 1977; Krebs et al., 1997), an increase in resource availability for 70 organisms feeding on a variety of resources should lead to an increased selectivity on their 71 preferred resources. These OFT predictions have been experimentally demonstrated in rodents 72 and wasps by Lacher (1982) and Armstrong \& Stamp (2003), respectively. While informative,

73 these intra-species experimental tests were effectively bound to a narrow range of resource 74 availability change (3-fold) and hardly represented the actual resources distribution in natural 75 ecosystems (controlled laboratory experiment; choice between two artificially-contrasted food 
sources). Testing the relationship between resource availability and selectivity in a biologically

77 realistic and relevant framework would thus require to study in situ a wide range of environmental

78 trophic conditions, a condition hardly met without working at the species level. Although

79 previous experimental validations of OFT predictions were only obtained at the individual and

80 population levels, we can expect the same kind of relationship at the species level following the

81 hypothesis developed by Evans et al. (2005). These authors predicted that an increase in total

82 resource availability would increase the abundance of rare resources that would then become

83 available in sufficient quantity to enable organisms to selectively feed on them. Consequently,

84 trophic selectivity of species would increase with resource availability in the field.

86 Trophic selectivity in animals has also been expected to vary with the qualities of resources

87 present in their environment (e.g. Cruz-Rivera \& Hay, 2000; Zandona et al., 2011). Indeed,

88 discriminating between the available resources would imply more benefit for the organism in an

89 environment where resources span a wide range of nutritional qualities than in an environment

90 where all resources have similar qualities. Many proxies of resource quality have been proposed,

91 including the widely used C:N and C:P ratios (Hessen et al., 2007; Hillebrand et al., 2008).

92 According to the ecological stoichiometry theory (Sterner \& Elser, 2002; Elser, 2006; Hessen et

93 al., 2013; Hood et al., 2014), organisms would select their trophic resources to minimize the

94 stoichiometric mismatch between their elemental composition and that of their consumed

95 resources. They are expected to feed selectively on the resources whose C:N and/or C:P ratios are

96 as close as possible to their own ratios to optimize their nutrient acquisition. This selective

97 stoichiometric choice would be achievable only in environments with resources of differing

98 qualities. As a consequence, trophic selectivity would increase with the diversity (i.e.

99 heterogeneity) of available resources in terms of stoichiometric quality. 
101 Although theory predicts that the availability as well as the heterogeneity in the quality of the

102 resources influences trophic selectivity, in situ explicit tests of their respective effects on selective

103 feeding are still lacking. The present paper aims to fill this gap by studying in situ the trophic

104 selectivity among species living along a gradient of resource availability. In this context, four

105 analytical challenges widely recognized in the literature must be addressed (Evans et al., 2005).

106 First, a wide environmental gradient in resource availability along which many closely related 107 species can be sampled is necessary. Indeed, earlier comparisons between two contrasted 108 environments are instructive (e.g. Huntsman et al., 2011), but lack support for generalization.

109 Second, the quantification of resource availability along the studied gradients was often limited to 110 coarse estimations using various databases and models without precise assessments of available

111 resources in the field (Gende et al., 2001; Kaspari, 2001; Birkhofer \& Wolters, 2012). Third, 112 accurate long-term diet estimation requires to integrate resource assimilation over a large period 113 of time. However, estimations of species diet relying on gut content analyses, measurements of 114 resource consumption or visual observations (Lacher, 1982; Armstrong \& Stamp, 2003;

115 Huntsman et al., 2011; Zandona et al., 2011) provide a snapshot of the diet at a given time and do 116 not consider differences in digestibility among resources (e.g. Trumble et al., 2003). Fourth, most

117 broad-scale studies did not account for the phylogenetic relatedness among species even though it 118 is now acknowledged that most biological traits are phylogenetically conserved (Felsenstein, 119 1985; Blomberg et al., 2003; Pienaar et al., 2013).

121 In the present paper, we addressed the aforementioned challenges through a dedicated sampling 122 design and the use of accurate analytical and statistical methods. We focused on aquatic isopod 123 species of the family Asellidae which represent ideal biological models due to their distribution 124 along a wide environmental gradient ranging from deep cave systems (among the most energy125 limited environments on Earth; Poulson \& Lavoie, 2000; Gibert \& Deharveng, 2002; Venarsky et 126 al., 2014) to highly-productive surface streams. Moreover, their phylogeny has been precisely 
127 described (Morvan et al., 2013), enabling to account for phylogenetic inertia. Based on a deep

128 knowledge of their habitat and ecology (Simon et al., 2003; Leberfinger et al., 2011; Mermillod-

129 Blondin et al., 2013; Eme et al., 2014; Francois et al., 2016a), a standardized sampling design was

130 built to evaluate the abundance as well as the stoichiometric quality (based on C:N and C:P ratios)

131 of all available resources in diverse environments. This precise characterization of trophic

132 resources was combined with diet determination to measure the degree of selectivity of each

133 species. Isopod diets were determined by analyzing the $\mathrm{C}$ and $\mathrm{N}$ stable isotope ratios of

134 individuals and their resources. The isotopic composition of an individual is a long-term

135 integrator of its trophic choices and reflects what has been actually assimilated in its tissues,

136 summarizing ingestion and digestibility of each resource (Peterson \& Fry, 1987; Fry \& Sherr,

137 1989; Traugott et al., 2013).

138

139 Based on 15 closely related species of Asellidae, we obtained an original dataset enabling to test

140 two predictions along one of the largest gradient of resource availability existing in natural

141 ecosystems. First, trophic selectivity of aquatic asellids should increase with resource availability

142 following the prediction of Evans et al. (2005). Second, trophic selectivity should increase with

143 the diversity in stoichiometric quality of resources according to the ecological stoichiometric 144 theory.

147 MATERIALS AND METHODS

148 Biological model

149 Our data set comprised 15 species of Asellidae collected in environments spanning a wide range

150 (from caves to surface streams) of freshwater habitats in Southern Europe (Table 1). Species of 151 isopods belonging to this family are known to feed on a wide range of food resources, including 152 coarse and fine particulate organic matter (CPOM and FPOM), filamentous algae, aquatic 
153 macrophytes, epilithic biofilm and periphyton (Moore, 1975; Marcus et al., 1978; Rossi \& Fano,

154 1979; Basset \& Rossi, 1987; Arakelova, 1996; Leberfinger et al., 2011; Francois et al., 2016a).

155 Given this diversity of food resources, we used a commonly accepted procedure which consists in

156 discriminating between broad food compartments (Simon et al., 2003; Leberfinger et al., 2011).

157 These compartments correspond to coarse particulate organic matter (CPOM; $1 \mathrm{~mm}<$ particle

158 size $<6 \mathrm{~mm}$ ), fine particulate organic matter (FPOM; particle size $<1 \mathrm{~mm}$ ), roots, algae,

159 sedimentary biofilm developed on sand particles $(200 \mu \mathrm{m}<$ particle size $<1000 \mu \mathrm{m})$, biofilm

160 attached to the debris of animal cuticle (epicuticular biofilm) and thick biofilm attached to

161 submerged rocks (epilithic periphyton).

163 Sampling

164 The 15 species were sampled from July to October 2011 in caves, springs and streams. Only one 165 focal asellid species was present in each sampling site. For each species, from 9 to 18 individuals 166 were collected (at sight or using the Bou-Rouch method (Bou, 1974) or a Surber sampler), except 167 for the species $P$. parvulus with only 4 sampled individuals (see Table S1 in Supporting 168 Information). In parallel, the trophic resources known to be edible by Asellidae were sampled in 169 each environment. This sampling consisted in 3 replicates per environment, in order to be 170 representative of the spatial heterogeneity. Following the approach of Huntsman et al. (2011),

171 each replicated sampling consisted in collecting on a depth of $1 \mathrm{~cm}$ all available resources 172 occurring on a standardized area $\left(256 \mathrm{~cm}^{2}\right)$. After sampling, both samples of trophic resources and 173 isopods were flash-frozen with liquid nitrogen in the field for conservation during the journey 174 back to the laboratory.

\section{Trophic resources in the environment}

177 At the laboratory, all collected trophic resources were unfrozen and sorted according to the food 178 categories described above by using nets of different mesh sizes (200 $\mu \mathrm{m}, 1 \mathrm{~mm}$ and $6 \mathrm{~mm}$ ). Food 
179 categories were then frozen, freeze-dried and weighted to obtain a dry mass of each trophic resource per square meter (g of Dry Weight (DW) $/ \mathrm{m}^{2}$ ) for each site (Table S2). All obtained 181 resource samples were then ground using a ball mill grinder (Retsch MM-200) for

182 homogenization before the determination of resource elemental composition (\%OC, \%N and \%P, 183 i.e. the organic carbon (OC), nitrogen and available phosphorus content of each resource, as \% of 184 dry mass; Table S2). For sedimentary biofilm and periphyton, samples were treated with $1 \mathrm{~N} \mathrm{HCl}$ 185 before OC analysis to remove carbonates using the 'capsule method', as described in Brodie et al. 186 (2011). Elemental composition was then measured alongside the determination of isotopic ratios 187 (see below), allowing to calculate the C:N stoichiometric molar ratio of each resource (Table S2). 188 The quantity of each resource (g of $\mathrm{DW} / \mathrm{m}^{2}$ ) and its elemental composition (\%OC) enabled to 189 calculate the OC content for each resource per site (g of OC sequestered in a given resource . $\mathrm{m}^{-2}$ ).

\section{Phosphorus content of isopods and trophic resources}

192 Chemical analyses were performed to determine the phosphorus content of isopods and of their 193 trophic resources (\% of P per dry mass). For isopods and trophic resources (except sedimentary 194 biofilm and periphyton), P content was determined on ground samples digested in an autoclave 195 for 30 minutes at $121^{\circ} \mathrm{C}$ and $15-20$ psi with potassium persulfate and sulfuric acid to convert all 196 phosphorus to orthophosphate. Then, orthophosphate content of each sample was determined by the molybdate/ascorbic acid blue method (Murphy \& Riley, 1958). For sedimentary biofilm and periphyton, as all fractions of total phosphorus are not available for the biota (Golterman, 2001), the quantity of $\mathrm{P}$ available for asellids was determined by measuring the available organic $\mathrm{P}$. Following Ni et al. (2016), available organic P was extracted from resource samples $(\mathrm{n}=3$ per resource type) with $\mathrm{NaOH} 1 \mathrm{M}$. After extraction during 16 hours, the supernatant was collected, its pH was stabilized with $\mathrm{HCl}(3.5 \mathrm{M})$ and the extracted $\mathrm{P}$ that has been converted in orthophosphate was quantified using the molybdate/ascorbic acid blue method (Murphy \& Riley, 1958). 
$\mathrm{C}$ and $\mathrm{N}$ stable isotope ratios were measured for all isopods (previously freeze-dried) and freezejoint analysis was not possible for sedimentary biofilm and periphyton samples which were previously treated for carbonate removal using $\mathrm{HCl}$ ('capsule method'). For these samples, we performed separate analyses to avoid any damage of the isotope ratio mass spectrometer with chloride. According to Francois et al. (2016a), the 'rinse method' (Brodie et al., 2011) was used for chloride removal before measurement of isotopic ratios. Elemental composition and stable isotope ratios of $\mathrm{C}$ and $\mathrm{N}$ were measured using an isotope ratio mass spectrometer (Isoprime100, Isoprime

214 Ltd, Manchester, UK) coupled in continuous flow with an elemental analyzer (Thermo FlashEA 215 1112, ThermoElectro, Milan, Italy). In-house standards calibrated against IAEA-N1, IAEA-N2, 216 IAEA-CH6 and IAEA-C3 reference materials were analyzed with the samples, and standard 217 deviations of replicate analyses were lower than $0.20 \%$. C and $\mathrm{N}$ stable isotope compositions were expressed as $\delta$ in \%o with V-PDB $\left(\delta^{13} \mathrm{C}\right)$ and Air $\left(\delta^{15} \mathrm{~N}\right)$ as standards.

\section{Diet determination}

221 The diets of the 15 species were determined by analyzing the $\mathrm{C}$ and $\mathrm{N}$ stable isotope signatures of 222 isopods and their available resources with the Bayesian mixing model SIAR (Parnell et al., 2010).

223 The model was run with 1 million of iterations, $50 \%$ of burn-in and a thinning of 250 . As the diet224 tissue discrimination has not been determined for isopod species, we used the commonly accepted 225 values of $2.54 \pm 1.27$ and $0.4 \pm 1.3$ for nitrogen $(\Delta 15 \mathrm{~N})$ and carbon isotope discrimination 226 ( $\Delta 13 C$ ), respectively (Vander Zanden \& Rasmussen, 2001; Post, 2002; Vanderklift \& Ponsard, 227 2003). The choice of discrimination factors for non-model organisms is tricky and may impact the results of the mixing model. The isoplots (Fig. S1) suggest that the value chosen for $\Delta 15 \mathrm{~N}$ may be underestimated for some groundwater species, as some individuals fall outside the source polygon in terms of $\delta^{15} \mathrm{~N}$ (exceeding by up to 2\%o the expected values) in four species ( $P$. arthrodilus, $B$. 
231 molinai, $P$. spelaeus and $P$. parvulus). Although a higher $\Delta 15 \mathrm{~N}$ would have corrected the

232 discrepancies in isoplots for these four species, it would not have significantly changed diet

233 estimations for these species. Thus, the commonly accepted value of $2.54 \pm 1.27$ for $\Delta 15 \mathrm{~N}$ was

234 used to be consistent in the analysis of the 15 species. Posterior probability distributions of the

235 SIAR models were checked for unimodality. Median and 95\% credibility interval were reported

236 for each resource contributing to the diet (Table S3).

237 To determine the sample size of consumers collected in each environment, we followed the 238 guidelines of Jackson et al. (2011) who recommend a minimum of 10 individuals to properly 239 quantify the species trophic niche, at the exception of $P$. parvulus for which only 4 individuals 240 could be collected. For this species, the small sample size implied a higher uncertainty in the diet 241 reconstruction, and a potential underestimation of trophic niche size.

242 Including too many resources in Bayesian mixing models can lead to confounding results (e.g.

243 inconsistent or bimodal posterior distributions). In this case, Hopkins \& Ferguson (2012) and 244 Phillips et al. (2014) advised to combine biologically related resources having similar isotopic 245 signatures to increase the predictive power of the model. Thus, FPOM and CPOM were combined 246 in a unique resource (hereafter 'FPOM + CPOM') when more than 3 resources were considered in 247 the diet of isopods and when the average $\delta^{13} \mathrm{C}$ and $\delta^{15} \mathrm{~N}$ of FPOM and CPOM differed by no more 248 than 1.3\%o. This resource combination successfully improved the diet determination for 2 species: 249 P. coiffaiti and P. ibericus. For one species (P. coiffaiti), we measured differences between the C 250 isotopic signatures of resources (algae) and consumers that were not consistent with the 251 discrimination factor $(\Delta 13 C=0.4 \pm 1.3)$. This discrepancy did not influence our results as 252 discussed in the Supporting Note S1. It is worth noting that the bayesian mixing models used for 253 diet reconstruction usually generate large confidence intervals, as they integrate all biological 254 uncertainties. If the bayesian mixing model does not properly converge, results are biased towards 255 the null generalist assumption, i.e. a diet composed of $n$ resources in proportion 1/n (Brett 2014). 256 In our dataset, only 3 out of the 15 reconstructed diets display a pattern close to this 
equiproportional null scenario (P. arthrodilus, $P$. granadensis and to a lesser extent B. peltatus), 258 which may indicate uncertainty in diet reconstruction. The 15 isoplots are displayed in the Fig. 259 S1.

\section{Estimated variables and data analyses}

262 Standardization of the availability of trophic resources

263 Trophic resources had contrasted elemental composition (e.g. the \%OC ranged from 0.06\% for 264 sedimentary biofilm per mass of dry sediment to $47 \%$ for roots). Thus, the absolute quantity of a 265 given resource (in g of $\mathrm{DW} / \mathrm{m}^{2}$ ) is not representative of its energetic significance for a consumer. 266 The OC content sequestered in a given resource provides a much more accurate estimation of this 267 significance and thus the availability of each trophic resource was expressed as amount of OC . $\mathrm{m}^{-}$ 2682.

\section{Indices of trophic selectivity}

270 Several indices have been proposed in the literature to measure the degree of selectivity of a 271 consumer (Hurlbert, 1978; Feinsinger et al., 1981; Smith, 1982). They all rely on a comparison

272 between the proportions of resources in the environment (i.e. here their relative abundances in

273 terms of OC content) and their respective proportions in the consumer diet. If these environment 274 and diet proportions match closely, this consumer is feeding non-selectively on all available 275 resources. If there is a strong mismatch between these proportions (i.e. between the availability 276 and the use of resources), this consumer is feeding highly selectively.

277 We evaluated the degree of selectivity of the 15 studied species by calculating the Proportional 278 Similarity index (PS) proposed by Feinsinger et al. (1981):

279 PS $=1-0.5 * \sum\left|\mathrm{q}_{\mathrm{i}}-\mathrm{p}_{\mathrm{i}}\right|$

280 where $p_{i}$ stands for the availability of the resource $i$ in the environment (i.e. the relative abundance 281 in terms of OC content) and $q_{i}$ stands for the dietary use of this resource $i$ (i.e. the proportion in 282 the diet, in terms of $\mathrm{C}$ and $\mathrm{N}$ atoms assimilated in the consumer tissues). This index measures the 
283 similarity between the distribution of resource availability and resource use. To highlight the

284 dissimilarity between these distributions (i.e. the selectivity), we modified PS to PS':

285 Trophic selectivity: PS' = 1 - PS

286 The obtained index PS' thus actually reflects the degree of consumer selectivity and ranges from 0 287 (non-selective feeding) to 1 (highly selective feeding). Two other selectivity indices were 288 proposed in the literature: the index B of Hurlbert (1978) and the index FT of Smith (1982). These 289 two indices (described in the Supporting Methods S1 and Table S1) were highly correlated with 290 the PS index (Spearman correlation coefficients $\rho=0.95$ and 0.98 for B and FT respectively).

291 Thus, we only presented the results obtained with the index PS'. To consider the uncertainty 292 inherent to Bayesian mixing models, for each species 1,000 diet proportion vectors (i.e. [ $\mathrm{p}_{1} ; \mathrm{p}_{2} ; \ldots$;

$293 \mathrm{p}_{\mathrm{n}}$ ] for $n$ resources contributing to the diet) were sampled from the posterior distributions output 294 by SIAR and subsequently used to draw a distribution of PS' values and calculate the 95\% 295 credibility interval for PS'.

296 Resource availability per site

297 Based on our OC quantifications, the resource availability (RA) in each sampling site was 298 estimated by the mass of OC per surface unit ( $\mathrm{g}$ of OC . $\mathrm{m}^{-2}$ ), summed over all collected resources 299 edible by asellids (an approach similar to Srivastava \& Lawton, 1998; Thompson \& Townsend, 300 2005).

\section{Quality of resources}

302 The quality of a given resource was estimated by the strength of the elemental imbalance between 303 this resource and the consumer according to the theory of ecological stoichiometry (Sterner \& 304 Elser, 2002; Frost et al., 2005; Hessen et al., 2013). The stronger is this elemental imbalance, the 305 less beneficial it is for the consumer to feed on this resource. For a given resource $\mathrm{i}$, this stoichiometric mismatch $\left(\mathrm{SM}_{\mathrm{i}(\mathrm{C}: \mathrm{N})}\right.$ or $\left.\mathrm{SM}_{\mathrm{i}(\mathrm{C}: \mathrm{P})}\right)$ was measured by the difference between the $\mathrm{C}: \mathrm{N}$ (or $\mathrm{C}: \mathrm{P}$ ) ratio of the resource $\mathrm{i}$ and the $\mathrm{C}: \mathrm{N}$ (or C:P) ratio of the consumer (Elser \& Hassett, 1994; 
308 Sterner \& Elser, 2002) (see Table 1 for the C:N and C:P of isopods and Table S2 for the C:N and $\mathrm{C}: \mathrm{P}$ of resources):

$\mathrm{SM}_{\mathrm{i}(\mathrm{C}: \mathrm{N})}=\mathrm{C}: \mathrm{N}_{\text {resource i }}-\mathrm{C}: \mathrm{N}_{\text {consumer }} \quad$ and $\mathrm{SM}_{\mathrm{i}(\mathrm{C}: \mathrm{P})}=\mathrm{C}: \mathrm{P}_{\text {resource i }}-\mathrm{C}: \mathrm{P}_{\text {consumer }}$

311 The Resource Diversity in terms of Quality for C:N (RDQual $\left.{ }_{\mathrm{C}: \mathrm{N}}\right)$ or for C:P (RDQual $\left.\mathrm{R}_{\mathrm{P} P}\right)$ was then

312 estimated in each environment by calculating the weighted variance $\left(\sigma^{2}\right)$ of the stoichiometric

313 mismatches in C:N or C:P of all available resources:

$314 \quad \sigma^{2}=\sum p_{i} \cdot\left(\mathrm{SM}_{\mathrm{i}(\mathrm{C}: \mathrm{N} \text { or C:P })}-\mu^{*}\right)^{2}$

315 where $\mu^{*}$ is the weighted mean of the SM of all resources weighted by their relative abundance $\mathrm{p}_{\mathrm{i}}$.

316 As the total number of available resources (RR; Resource Richness) differed between sites, this

317 weighted variance was corrected for sample size and transformed in a weighted standard

318 deviation:

319 Resource Diversity in terms of Quality: RDQual (C:N or C:P) $_{1}=\operatorname{sqrt}\left(\sigma^{2} /((\mathrm{RR}-1) / \mathrm{RR})\right)$ (5)

320 This index measures the heterogeneity in the stoichiometric mismatches of all available resources

321 in the environment. Low RDQual ${ }_{(\mathrm{C}: \mathrm{N} \text { or C:P) }}$ indicates that all available resources in the environment

322 have similar stoichiometric qualities for the consumer. On the opposite, RDQual $\mathrm{C}_{(\mathrm{C}: \mathrm{N} \text { or C:P) }}$ increases

323 when the stoichiometric qualities for the consumer increasingly diverge among available

324 resources and when these resources having different stoichiometric qualities are available in even

325 proportions (this latter property is similar to an evenness index which is maximal when all

326 resources are in even proportions and minimal when one resource is predominant). According to

327 our prediction, trophic selectivity would increase when RDQual (C:N or C:P) $_{\text {increases. }}$

328 Number of trophic resources

329 In addition to Resource Availability (RA) and Resource Diversity in terms of Quality (RDQual ${ }_{(\mathrm{C}: \mathrm{N}}$

330 or C:P)), the number of trophic resources present in each environment can also influence trophic

331 selectivity by a purely probabilistic effect. Indeed, an increase in the number of resources

332 enhances the trophic choice and influences the probability of selective feeding by organisms,

333 independently of resources quality. To include this probabilistic hypothesis in our data analyses, 
334 the Resource Diversity in terms of Quantity (RDQuant, Table S1) was estimated in each

335 environment with a Shannon index that integrates resource number and evenness (relative

336 abundance) across all available resources:

337 Resource Diversity in terms of Quantity: RDQuant $=-\sum \mathrm{p}_{\mathrm{i}} \cdot \ln \left(\mathrm{p}_{\mathrm{i}}\right)$

338 where $\mathrm{p}_{\mathrm{i}}$ is the relative abundance of the resource $\mathrm{i}$ in the environment (relative to the total

339 amount of OC).

340 Phylogenetic analyses

341 Evaluating the relative influences of the Resource Availability (RA) and the Resource Diversity in

342 terms of Quality (RDQual ${ }_{(\mathrm{C}: \mathrm{N} \text { or C:P) }}$ ) and in terms of Quantity (RDQuant) on trophic selectivity

343 needs to take into account the phylogenetic relationships among the 15 species. Taking

344 advantages of whole transcriptome sequencing for the 15 species considered in the present study

345 (Francois et al., 2016b), we extracted a set of 386 1-to-1 orthologous gene alignments present in

346 all species. The concatenated alignment was used to reconstruct a phylogram with phyML with a

347 GTR+G+I model of evolution (Guindon et al., 2010). Using this topology, we estimated a

348 chronogram with mcmctree (Yang 2007) using default parameters, two independent runs to check

349 chains convergences and setting the divergence between the Bragasellus and Proasellus to be not

350 older than 150 MYA.

351 Statistical analyses

352 According to the recommendations of Warton \& Hui (2011) for proportion data, the trophic

353 selectivity index PS' has been logit-transformed prior to statistical analyses. RA and RDQual ${ }_{C: P}$

354 have been log-transformed prior to statistical analyses to correct for non-normality of the data. We

355 checked for multi-collinearity among the four environmental variables (RA, RDQual ${ }_{\mathrm{C}: \mathrm{N}}$,

356 RDQual $_{\mathrm{C}: \mathrm{P}}$ and RDQuant) using variance inflation factors (VIF) and found them to be in

357 acceptable range (all VIF $<2.4$; see Zuur et al., 2010). We used Phylogenetic Generalized Least-

358 Squares models (PGLS; Martins \& Hansen, 1997) to evaluate the influence of the four

359 environmental variables on trophic selectivity while accounting for the phylogenetic relationships 
among the focal species (using the R package caper). Blomberg's $\mathrm{K}$ was estimated using the

361 function phylosig in phytools R package (Revell, 2012). As a dataset based on 15 asellid species

362 did not enable to statistically test the influence of four environmental variables and their

363 interactions on trophic selectivity, we decided to perform two separate analyses with RA,

364 RDQual $_{\mathrm{C:N}}$ and RDQuant as explaining variables in one hand and RA, RDQual ${ }_{\mathrm{C}: \mathrm{P}}$ and RDQuant as

365 explaining variables in another hand. For each analysis, we performed a procedure of model

366 selection based on information theory (Burnham \& Anderson, 2002) and the ranking of models

367 according to Akaike's Information Criterion corrected for small sample size (AICc, MuMIn R

368 package), starting from the most comprehensive model (including all interactions). We checked

369 that the order of entry of each variable into the PGLS models did not change significantly the

370 results. The adjusted McFadden's pseudo- $\mathrm{R}^{2}$ (McFadden, 1974) was computed for all tested

371 models to provide for a comparable estimation of the amount of explained variance among

372 models with different number of parameters. The normality of the residuals of the final 'best'

373 model (with the smallest AICc) was checked.

374 All data analyses were performed with R 3.4 software (R Development Core Team 2016).

\section{RESULTS}

\section{Trophic resources, isopod diets and trophic selectivity}

379 Our dataset comprised 15 environments characterized by a wide range of resource availability 380 (RA) with amounts of OC . $\mathrm{m}^{-2}$ varying from $1.3 \mathrm{~g}$ to $57.6 \mathrm{~g}$ (Fig. 1, Tables S1 \& S2). The

381 Resource Diversity in terms of stoichiometric Quality was also contrasted among environments 382 with RDQual ${ }_{\mathrm{C}: \mathrm{N}}$ indexes ranging between 1.1 and 20.1, and RDQual ${ }_{\mathrm{C}: \mathrm{P}}$ indexes ranging between 3834.0 and 633.4 (Table S1). There was no collinearity between the four predictor variables RA, RDQual $_{\mathrm{C}: \mathrm{N}}, \mathrm{RDQual}_{\mathrm{C}: \mathrm{P}}$ and RDQuant (VIF $=1.65,1.60,2.44$ and 1.49 respectively). Seven trophic resources were collected and quantified in the environments. Three resources (epicuticular 
386 biofilm, periphyton and algae) were found in only one or two environments whereas three

387 resources (fine and coarse particulate organic matter, and sedimentary biofilm) were present in

388 almost all environments (Table 2, Fig. 2). Each trophic resource was dominant (> 50\%) in at least

389 one environment, at the exception of periphyton and algae (Table 2).

390 Isotopic measurements and analyses using Bayesian mixing models showed that all available

391 trophic resources were found in the diets of at least one asellid species (Fig. 2, Table 2). For the

392 three resources found in almost all environments (fine and coarse particulate organic matter, and

393 sedimentary biofilm), their contributions to animal diets widely varied across species (Fig. 2). For

394 example, the sedimentary biofilm could be minor (<10\%) or dominant $(>50 \%)$ in the diets of

395 asellid species.

396 The PS' trophic selectivity indexes based on the match between isopod diets and resource 397 availabilities ranged from 0.042 to 0.919 (Fig. 1, Table S1). The dataset thus comprised non398 selective feeding (PS' close to 0) and highly selective feeding (PS' close to 1) species of isopods.

\section{Relationships between trophic selectivity and environmental variables}

401 The first procedure of model selection starting from the comprehensive model including resource 402 availability (RA), resource diversity in terms of quantity (RDQuant) and in terms of quality based 403 on C:N ratios (RDQual ${ }_{\mathrm{C}: \mathrm{N}}$ ) and all interactions as predictors of trophic selectivity (Table 3) 404 resulted in the selection of a model with the amount of available resources (RA) as unique 405 predictor of trophic selectivity (PS') (PGLS; P-value $=0.0031$ and $\mathrm{R}^{2}=0.46$; equivalent to Fig. 406 3a). A comparable result was obtained when resource diversity in terms of quality based on C:P 407 ratios (RDQual ${ }_{\mathrm{C}: \mathrm{P}}$ ) replaced $\mathrm{RDQual}_{\mathrm{C}: \mathrm{N}}$ as predictor of trophic selectivity (Table S4). PS' was 408 positively correlated with RA (Fig. 3a). PS' was not correlated with the resource diversity in terms 409 of quality for C:N (RDQual ${ }_{C: N}$, Fig. 3c) or for C:P (RDQual ${ }_{C: P}$, Fig. 3d), neither with the resource 410 diversity in terms of quantity (RDQuant, Fig. 3b). Trophic selectivity showed no phylogenetic 411 signal among the 15 species (Blomberg’s $\mathrm{K}=0.09$, P-value $=0.94$; Blomberg et al. 2003). 
412 Among the 15 species studied, we found that 4 out of the 5 species living in environments with

413 more than $25 \mathrm{~g}$ of OC. $\mathrm{m}^{-2}$ were selective-feeders (i.e. with a PS'>0.5, Fig. 1): P. solanasi, $P$.

414 beticus, $P$. ibericus and $B$. peltatus. These species always fed selectively on resource types that

415 were not dominant in the environment. For example, the diet of $P$. beticus comprised $56 \%$ of

416 sedimentary biofilm whereas this resource type represented less than $2 \%$ of OC resources in the

417 environment (Fig. 2). There was a tendency across species for feeding selectively on sedimentary

418 biofilm but other resource types were also selected. If $P$. solanasi and $P$. beticus selected solely

419 sedimentary biofilm in the environment, the two other selective-feeding species fed selectively on

4202 or more resources: sedimentary biofilm and roots for P. ibericus, and CPOM, FPOM and

421 sedimentary biofilm for B. peltatus.

\section{DISCUSSION}

425 The dataset collected for the present study allowed to test the influence of trophic environmental

426 conditions (resource availability and diversity) on the trophic selectivity of aquatic speciesacross

427 a broad range of environments. In this dataset, the absence of collinearity between the predictor

428 variables allowed to discriminate the relative influences of trophic conditions on selectivity.

429 Coupling an accurate quantification of trophic resources in a wide range of environments with a

430 fine determination of animal diets using stable isotopes showed that the amount of available

431 resources rather than the diversity of resource (in terms of quality and quantity, respectively

432 RDQual $_{(\mathrm{C}: \mathrm{N}}$ or C:P) and RDQuant) increases trophic selectivity of aquatic isopod species. The

433 positive relationship between resource availability and trophic selectivity was probably uncovered

434 in this study thanks to the wide range of resource availability studied (from 1.3 to $57.6 \mathrm{~g}$ of OC .

$435 \mathrm{~m}^{-2}$ ) which incorporated both surface and cave streams, these latter being considered as one of the

436 most energy-limited environments on Earth (Poulson \& Lavoie, 2000; Simon et al., 2003;

437 Venarsky et al., 2012, 2014). By contrasting environmental conditions, we demonstrated that 
438 species tend to feed non-selectively at lower bounds of resource availability whereas selective-

439 feeding species were detected in resource-rich environments. Intraspecific niche partitioning

440 (sensu Bolnick et al., 2002) could theoretically affect this pattern, as non-selective species can be

441 composed of individuals feeding selectively on different resources. However, non-selective

442 species at the lower bound of resource availability do not display particularly dispersed

443 individuals (see the isoplots in Fig S1; except for B.molinai), neither do they display distinct

444 groups of individuals feeding on (i.e. isotopically close to) different resources, suggesting that the

445 observed selectivity pattern should be similar at the species and individual levels. The analysis

446 also suggested that trophic selectivity was not phylogenetically conserved among the focal

447 species.

449 One major finding of the present study is the demonstration of a positive relationship between 450 resource availability and trophic selectivity in aquatic isopods. This relationship supports the 451 hypothesis that trophic selectivity was low in resource-poor environments probably because 452 species cannot fulfill their energy requirements by foraging on a reduced set of the available 453 resources (Thompson \& Colgan, 1990; Tinker et al., 2008). Nevertheless, the mechanisms 454 explaining selective feeding by isopods in resource-rich environments remain elusive. Our results 455 did not validate the mechanism proposed by Evans et al. (2005) to explain the positive 456 relationship between resource availability and trophic selectivity. These authors hypothesized that 457 an increase in total resource availability could increase some rare resources which would then 458 become available in sufficient quantity for species to selectively feed on them. However, 459 sedimentary biofilm was selected by many selective-feeding isopods in resource-rich 460 environments even when the amount of this trophic resource was lower than in resource-poor 461 environments (eg. see P. ibericus, Fig. 2). These results did not give a strong support to the 462 mechanism presented by Evans et al. (2005) to explain the positive relationship between resource 463 availability and trophic selectivity. The mechanisms leading to increased trophic selectivity with 
464 increasing resource availability might also have been associated with other ecological factors. For

465 instance, the species-energy theory indicates that species richness increases with resource

466 availability in the environment (Bonn et al., 2004). In such condition, interactions among species

467 would be stronger in resource-rich than in resource-poor environments, which could increase

468 niche partitioning among species (MacArthur \& Levins, 1967). This niche partitioning for food

469 and/or habitat would therefore enhance the mismatch between the relative abundances of

470 resources in species diet and their relative abundances in the environment (i.e. leading to an

471 increased trophic selectivity). For example, the microhabitat partitioning reported for marine

472 amphipods to avoid competitive exclusion and predation (Cruz-Rivera \& Hay, 2000; Best \&

473 Stachowicz, 2014) indicates that each amphipod species does not have access to the whole range

474 of resources present in the environment. We can expect the same mechanism to occur in our

475 experiment for isopod species living in resource-rich environments where biotic interactions are

476 expected to be strong. Demonstrating this mechanism will represent a significant advance in our

477 understanding of ecosystem structure and functioning, but represents a difficult task as it requires

478 to finely describe the spatial distributions of all species in each environment but also the biotic

479 interactions among these species.

481 Our results demonstrated that trophic selectivity was associated with resource availability but not

482 with the diversity (i.e. heterogeneity) in resource quality. We expected that the stoichiometric 483 constraints would have determined the resource used by consumers in accordance with the 484 stoichiometric ecological theory (Sterner \& Elser, 2002). In other words, a high diversity of 485 resource stoichiometric qualities would have generated selective feeding whereas non-selective 486 feeding was expected in environments harboring resources of comparable stoichiometric qualities.

487 These predictions were not validated because asellid species fed selectively or non-selectively 488 regardless of the diversity in resource quality in their environment. For example, three species of 489 selective feeders (PS' > 0.5) were observed in environments displaying comparatively low 
490 diversity in resource quality for C:N (RDQual ${ }_{\mathrm{C}: \mathrm{N}}<5$ in our dataset, figure $3 \mathrm{~b}$ ), whereas no

491 selective feeding was expected under the stoichiometric hypothesis in these environments.

492 Admittedly, some criticisms can be drawn concerning the use of stoichiometric C:N or C:P ratios

493 to evaluate resource quality. Measuring C:N and C:P ratios of a given trophic resource as a 'bulk'

494 can skew our analyses, as detritivores can selectively ingest and/or assimile only a subfraction of

495 the considered pool (e.g. the conditioned leaves colonized by fungi; Constantini and Rossi, 1995).

496 Besides, detrimental chemicals such as phenolic compounds may reduce the palatability of

497 trophic resources without affecting their C:N and C:P ratios (Oates et al., 1980; Dorenbosch \&

498 Bakker, 2011) and compounds which cannot be synthetized by animals such as sterols or essential

499 fatty acids may influence resource selectivity in a different way than C: $\mathrm{N}$ and C:P ratios (Wagner

500 et al., 2013; Sperfeld et al., 2017). However, our results gave support to the idea of a dietary

501 mixing strategy in asellids because most selective-feeding species (eg. P. ibericus and B. peltatus)

502 selected at least 2 trophic resources that were largely contrasted in terms of C:N and C:P (e.g.

503 averaged C:N : $10.2 \pm 4.2$ for sedimentary biofilms, $21.4 \pm 8.2$ for FPOM, $22.4 \pm 11.8$ for roots,

504 and $29.3 \pm 18.9$ for CPOM; Table S2). This suggests that asellid species need to mix trophic

505 resources for nutrient acquisition (nutrient complementation hypothesis; Hägele \& Rowell-Rahier,

506 1999). Thus, we can assume that trophic selectivity in aquatic isopod species was not driven by

507 the stoichiometric diversity of available resources because of the need for essential compounds

508 that were not contained in the trophic resources having the lowest $\mathrm{C}: \mathrm{N}$ or $\mathrm{C}: \mathrm{P}$ mismatches with

509 organisms (ie. best resources in terms of stoichiometric quality). To address this topic, use of

510 specific markers such as amino acids and fatty acids and their isotopic compositions would be

511 pertinent to have more precise reconstructions of asellid diets and more precise quantifications of

512 the diversity of trophic resources in the environment than those obtained from bulk analyses of $\mathrm{N}$

513 and C (Bec et al., 2011). 
515 Although we observed that asellid species could selectively feed on several trophic resources,

516 sedimentary biofilm was generally found in higher proportion in the diet of selective-feeding

517 isopods than in their environment. Besides, a previous study by Francois et al. (2016a)

518 demonstrated that two asellid species exhibited a strong specialization (i.e. a higher performance;

519 Irschick et al., 2005; Whitfield et al., 2009; Devictor et al., 2010; Poisot et al., 2011) on

520 sedimentary biofilm. Feeding experiments in the laboratory showed that both species assimilated

521 about 10 times more carbon and at least 4 times more nitrogen from sedimentary biofilm than

522 from coarse and fine particulate organic matter. Thus, the fact that selective feeding on

523 sedimentary biofilm was common in the present study might have resulted from a positive fitness

524 consequence for isopods to use this resource. Nevertheless, we cannot conclude from the present

525 experiment that selective feeding on sedimentary biofilm conferred a better performance to asellid

526 species than feeding on other resources without measurements of the fitness of all isopod species

527 when feeding on individual resources present in their environments. Coupling our original dataset

528 on trophic selectivity of asellid species with measures of their performance on the available

529 resources would provide a unique opportunity to document and understand the relationship

530 between trophic specialization and selectivity in regard to resource availability.

535 FIGURES CAPTION

536 Figure 1: Phylogenetic tree of the 15 isopod species, plotted along with the resource 537 availability in their environments and their trophic selectivity PS'. Resource availability in 538 the environment is expressed in grams of Organic Carbon (OC) per square meter.

540 Figure 2: Relative abundance and use of trophic resources in the 15 sampling sites. 
541 For each site, the upper panel presents the relative abundance of all available resources in the

542 environment (in \%; see Methods for details on the underlying calculations), while the lower panel

543 presents the contribution of these resources to the diet of isopods (in \%).

544 For a given environment, the total resource availability (indicated on the left hand side of the

545 barplots, in grams of Organic Carbon per square meter) is summed over all available resources.

546 Environments (and their corresponding species) are sorted by increasing resource availability.

548 Figure 3: Relationships between the trophic selectivity PS' and (a) the Resource Availability 549 (RA) as grams of OC . $\mathbf{m}^{-2}$; (b) the Resource Diversity in terms of Quantity (RDQuant); (c) 550 and (d) the Resource Diversity in terms of stoichiometric Quality based on C:N and C:P 551 ratios respectively (RDQual ${ }_{\mathrm{C}: \mathrm{N}}$ and $\left.\mathrm{RDQual}_{\mathrm{C}: \mathrm{P}}\right)$.

552 These plots present biological data prior to transformation. Only significant regression lines are 553 drawn. See M\&M for details on the credibility intervals drawn for PS’.

ACKNOWLEDGEMENTS

557 We thank the following collaborators and organizations for their precious help in collecting

558 biological material: Alhama de Granada municipality, M. Isabel Carreira, T. Datry, D. Eme, Cueva 559 de Valporquero, Junta de Andalucia (Hundidero - Gato) and Rafael Orozco. We are grateful to 560 David Eme for valuable comments on statistical analyses and Pierre Marmonier for a careful 561 reading and editing of the manuscript. We thank the editors and the anonymous reviewers for their 562 valuable comments on an earlier version of this manuscript.

\section{AUTHORS' CONTRIBUTIONS}

All authors conceived the ideas and designed methodology; CF, LS, TL, FM and CD collected

566 field data; CF, FMB and LS carried out the elemental and stable isotope analyses, analysed the 
567 data and wrote the manuscript. All authors contributed critically to the drafts and gave final

568 approval for publication.

569

\section{DATA ACCESSIBILITY}

571 Datasets supporting this article are available in the electronic supplementary material. Raw

572 isotopic data are available from the Dryad Digital Repository

573 (https://doi.org/10.5061/dryad.v9s4mw6qw).

574

\section{COMPETING INTERESTS}

576 We have no competing interests.

577

578 FUNDING

579 This work was supported by grants from the Agence Nationale de la Recherche (ANR-08-JCJC-

580 0120-01 DEEP) and the Centre National de la Recherche Scientifique (APEGE 2012 581 'Stoichiogenomics' No. 70632 and EC2CO 2013-2014 'Ecosphere Continentale et Cotiere' 582 'CoCoNutS' project).

583

584

585

\section{REFERENCES}

587 Arakelova, E. S. (1996). Feeding strategy and energy allocation in Asellus aquaticus L. Russian 588 Journal of Aquatic Ecology, 5, 65-73.

589

590 Armstrong, T. R., \& Stamp, N. E. (2003). Effects of prey quantity on predatory wasps (Polistes

591 dominulus) when patch quality differs. Behavioral ecology and sociobiology, 54(3), 310-319.

592 https://doi.org/10.1007/s00265-003-0624-1 
594 Basset, A., \& Rossi, L. (1987). Relationships between trophic niche breadth and reproductive 595 capabilities in a population of Proasellus coxalis Dollfus (Crustacea: Isopoda). Functional 596 Ecology, 13-18. https://doi.org/10.2307/2389352

598 Bec, A., Perga, M. E., Koussoroplis, A., Bardoux, G., Desvilettes, C., Bourdier, G., \& Mariotti, A. 599 (2011). Assessing the reliability of fatty acid-specific stable isotope analysis for trophic studies.

600 Methods in Ecology and Evolution, 2(6), 651-659. https://doi.org/10.1111/j.2041-

601 210X.2011.00111.X

602

603 Best, R. J., \& Stachowicz, J. J. (2014). Phenotypic and phylogenetic evidence for the role of food 604 and habitat in the assembly of communities of marine amphipods. Ecology, 95(3), 775-786.

605 https://doi.org/10.1890/13-0163.1

606

607 Birkhofer, K., \& Wolters, V. (2012). The global relationship between climate, net primary

608 production and the diet of spiders. Global Ecology and Biogeography, 21(2), 100-108.

609 https://doi.org/10.1111/j.1466-8238.2011.00654.x

610

611 Blomberg, S. P., Garland Jr, T., \& Ives, A. R. (2003). Testing for phylogenetic signal in

612 comparative data: behavioral traits are more labile. Evolution, 57(4), 717-745.

613 https://doi.org/10.1111/j.0014-3820.2003.tb00285.x

614

615 Bolnick, D. I., Yang, L. H., Fordyce, J. A., Davis, J. M., \& Svanbäck, R. (2002). Measuring

616 individual-level resource specialization. Ecology, 83(10), 2936-2941.

617 https://doi.org/10.1890/0012-9658(2002)083[2936:MILRS]2.0.CO;2 
619 Bou, C. (1974). Methods to sample in interstitial groundwaters (Les méthodes de récolte dans les 620 eaux souterraines interstitielles). Annls Spéléol, 29, 611-619.

621

622 Brett, M. T. (2014). Resource polygon geometry predicts Bayesian stable isotope mixing model 623 bias. Marine Ecology Progress Series, 514, 1-12. https://doi.org/10.3354/meps11017 624

625 Brodie, C. R., Leng, M. J., Casford, J. S., Kendrick, C. P., Lloyd, J. M., Yongqiang, Z., \& Bird, M. 626 I. (2011). Evidence for bias in C and N concentrations and $\delta 13 \mathrm{C}$ composition of terrestrial and 627 aquatic organic materials due to pre-analysis acid preparation methods. Chemical Geology, 282(3628 4), 67-83. https://doi.org/10.1016/j.chemgeo.2011.01.007

629

630 Burnham, K. P., \& Anderson, D. R. (2002). Formal inference from more than one model: 631 multimodel inference (MMI). Model Sel. Multimodel inference. A practical information-theoretic 632 approach, 2nd edn. Springer, New York.

633

634 Chesson, J. (1978). Measuring preference in selective predation. Ecology, 59(2), 211-215.

635 https://doi.org/10.2307/1936364

636

637 Constantini, M. L., \& Rossi, L. (1995). Role of fungal patchiness on vegetal detritus in the trophic 638 interactions between two brackish detritivores, Idotea baltica and Gammarus insensibilis.

639 Hydrobiologia, 316(2), 117-126. https://doi.org/10.1007/BF00016893 640 
641 Cruz-Rivera, E., \& Hay, M. E. (2000). Can quantity replace quality? Food choice, compensatory

642 feeding, and fitness of marine mesograzers. Ecology, 81(1), 201-219.

643 https://doi.org/10.1890/0012-9658(2000)081[0201:CQRQFC]2.0.CO;2

644

645 Devictor, V., Clavel, J., Julliard, R., Lavergne, S., Mouillot, D., Thuiller, W., ... \& Mouquet, N.

646 (2010). Defining and measuring ecological specialization. Journal of Applied Ecology, 47(1), 15-

647 25. https://doi.org/10.1111/j.1365-2664.2009.01744.x

648

649 Dorenbosch, M., \& Bakker, E. S. (2011). Herbivory in omnivorous fishes: effect of plant

650 secondary metabolites and prey stoichiometry. Freshwater Biology, 56(9), 1783-1797.

651 https://doi.org/10.1111/j.1365-2427.2011.02618.x

652

653 Elser, J. J., \& Hassett, R. P. (1994). A stoichiometric analysis of the zooplankton-phytoplankton

654 interaction in marine and freshwater ecosystems. Nature, 370(6486), 211.

655 https://doi.org/10.1038/370211a0

656

657 Elser, J. (2006). Biological stoichiometry: a chemical bridge between ecosystem ecology and 658 evolutionary biology. The American Naturalist, 168(S6), S25-S35. https://doi.org/10.1086/509048 659

660 Eme, D., Malard, F., Colson-Proch, C., Jean, P., Calvignac, S., Konecny-Dupré, L., ... \& Douady, 661 C. J. (2014). Integrating phylogeography, physiology and habitat modelling to explore species 662 range determinants. Journal of biogeography, 41(4), 687-699. https://doi.org/10.1111/jbi.12237 663 
664 Evans, K. L., Warren, P. H., \& Gaston, K. J. (2005). Species-energy relationships at the

665 macroecological scale: a review of the mechanisms. Biological Reviews, 80(1), 1-25.

666 https://doi.org/10.1017/S1464793104006517

667

668 Feinsinger, P., Spears, E. E., \& Poole, R. W. (1981). A simple measure of niche breadth. Ecology,

669 62(1), 27-32. https://doi.org/10.2307/1936664

670

671 Felsenstein, J. (1985). Phylogenies and the comparative method. The American Naturalist,

672 125(1), 1-15. https://doi.org/10.1086/284325

673

674 Francois, C. M., Mermillod-Blondin, F., Malard, F., Fourel, F., Lécuyer, C., Douady, C. J., \&

675 Simon, L. (2016). Trophic ecology of groundwater species reveals specialization in a low-

676 productivity environment. Functional Ecology, 30(2), 262-273. https://doi.org/10.1111/1365-

$677 \quad \underline{2435.12484}$

678

679 Francois, C. M., Duret, L., Simon, L., Mermillod-Blondin, F., Malard, F., Konecny-Dupré, L., ...

680 \& Lefébure, T. (2016). No evidence that nitrogen limitation influences the elemental composition

681 of isopod transcriptomes and proteomes. Molecular biology and evolution, 33(10), 2605-2620.

682 https://doi.org/10.1093/molbev/msw131

683

684 Frost, P. C., Evans-White, M. A., Finkel, Z. V., Jensen, T. C., \& Matzek, V. (2005). Are you what

685 you eat? Physiological constraints on organismal stoichiometry in an elementally imbalanced

686 world. Oikos, 109(1), 18-28. https://doi.org/10.1111/j.0030-1299.2005.14049.x

687 
688 Fry, B., \& Sherr, E. B. (1989). $\delta 13$ C measurements as indicators of carbon flow in marine and 689 freshwater ecosystems. In Stable isotopes in ecological research (pp. 196-229). Springer, New 690 York, NY.

691

692 Gende, S. M., Quinn, T. P., \& Willson, M. F. (2001). Consumption choice by bears feeding on 693 salmon. Oecologia, 127(3), 372-382. https://doi.org/10.1007/s004420000590

694

695 Gibert, J., \& Deharveng, L. (2002). Subterranean Ecosystems: A Truncated Functional

696 Biodiversity. BioScience, 52(6), 473-481. https://doi.org/10.1641/0006-

697 3568(2002)052[0473:SEATFB]2.0.CO;2

698

699 Golterman, H. L. (2001). Fractionation and bioavailability of phosphates in lacustrine sediments: 700 a review. Limnetica, 20(1), 15-29.

701

702 Guindon, S., Dufayard, J. F., Lefort, V., Anisimova, M., Hordijk, W., \& Gascuel, O. (2010). New 703 algorithms and methods to estimate maximum-likelihood phylogenies: assessing the performance 704 of PhyML 3.0. Systematic biology, 59(3), 307-321. https://doi.org/10.1093/sysbio/syq010 705

706 Hägele, B. F., \& Rowell-Rahier, M. (1999). Dietary mixing in three generalist herbivores: nutrient 707 complementation or toxin dilution? Oecologia, 119(4), 521-533.

708 https://doi.org/10.1007/s004420050815 
710 Hessen, D. O., Jensen, T. C., Kyle, M., \& Elser, J. J. (2007). RNA responses to N-and P-

711 limitation; reciprocal regulation of stoichiometry and growth rate in Brachionus. Functional

712 Ecology, 21(5), 956-962. https://doi.org/10.1111/j.1365-2435.2007.01306.x

713

714 Hessen, D. O., Elser, J. J., Sterner, R. W., \& Urabe, J. (2013). Ecological stoichiometry: an

715 elementary approach using basic principles. Limnology and Oceanography, 58(6), 2219-2236.

716 https://doi.org/10.4319/lo.2013.58.6.2219

717

718 Hillebrand, H., Frost, P., \& Liess, A. (2008). Ecological stoichiometry of indirect grazer effects on

719 periphyton nutrient content. Oecologia, 155(3), 619-630. https://doi.org/10.1007/s00442-007-

$720 \quad \underline{0930-9}$

721

722 Hopkins III, J. B., \& Ferguson, J. M. (2012). Estimating the diets of animals using stable isotopes

723 and a comprehensive Bayesian mixing model. PloS one, 7(1), e28478.

724 https://doi.org/10.1371/journal.pone.0028478

725

726 Huntsman, B. M., Venarsky, M. P., Benstead, J. P., \& Huryn, A. D. (2011). Effects of organic

727 matter availability on the life history and production of a top vertebrate predator (Plethodontidae:

728 Gyrinophilus palleucus) in two cave streams. Freshwater Biology, 56(9), 1746-1760.

729 https://doi.org/10.1111/j.1365-2427.2011.02609.x

730

731 Hurlbert, S. H. (1978). The measurement of niche overlap and some relatives. Ecology, 59(1), 67-

732 77. https://doi.org/10.2307/1936632

733 
734 Irschick, D., Dyer, L., \& Sherry, T. W. (2005). Phylogenetic methodologies for studying

735 specialization. Oikos, 110(2), 404-408. https://doi.org/10.1111/j.0030-1299.2005.13927.x

736

737 Jackson, A. L., Inger, R., Parnell, A. C., \& Bearhop, S. (2011). Comparing isotopic niche widths

738 among and within communities: SIBER-Stable Isotope Bayesian Ellipses in R. Journal of Animal

739 Ecology, 80(3), 595-602. https://doi.org/10.1111/j.1365-2656.2011.01806.x

740

741 Kaspari, M. (2001). Taxonomic level, trophic biology and the regulation of local abundance.

742 Global Ecology and Biogeography, 10(3), 229-244. https://doi.org/10.1046/j.1466-

$743 \quad$ 822X.2001.00214.X

744

745 Lacher Jr, T. E., Willig, M. R., \& Mares, M. A. (1982). Food preference as a function of resource

746 abundance with multiple prey types: an experimental analysis of optimal foraging theory. The

747 American Naturalist, 120(3), 297-316. https://doi.org/10.1086/283992

748

749 Leberfinger, K., Bohman, I., \& Herrmann, J. A. N. (2011). The importance of terrestrial resource

750 subsidies for shredders in open-canopy streams revealed by stable isotope analysis. Freshwater

751 Biology, 56(3), 470-480. https://doi.org/10.1111/j.1365-2427.2010.02512.x

752

753 McFadden D. Conditional logit analysis of qualitative choice behavior. Pp. 105-142 in P.

754 Zarembka (ed.), Frontiers in Econometrics. Academic Press. 1974.

755

756 Marcus, J. H., Sutcliffe, D. W., \& Willoughby, L. G. (1978). Feeding and growth of Asellus

757 aquaticus (Isopoda) on food items from the littoral of Windermere, including green leaves of 
758 Elodea canadensis. Freshwater Biology, 8(6), 505-519. https://doi.org/10.1111/j.1365-

$759 \quad$ 2427.1978.tb01473.x

760

761 Martins, E. P., \& Hansen, T. F. (1997). Phylogenies and the comparative method: a general

762 approach to incorporating phylogenetic information into the analysis of interspecific data. The

763 American Naturalist, 149(4), 646-667. https://doi.org/10.1086/286013

764

765 Mermillod-Blondin, F., Lefour, C., Lalouette, L., Renault, D., Malard, F., Simon, L., \& Douady,

766 C. J. (2013). Thermal tolerance breadths among groundwater crustaceans living in a thermally

767 constant environment. Journal of Experimental Biology, 216(9), 1683-1694.

768 https://doi.org/10.1242/jeb.081232

769

770 Moore, J. W. (1975). The role of algae in the diet of Asellus aquaticus L. and Gammarus pulex L.

771 The Journal of Animal Ecology, 719-730. https://doi.org/10.2307/3714

772

773 Morvan, C., Malard, F., Paradis, E., Lefébure, T., Konecny-Dupré, L., \& Douady, C. J. (2013).

774 Timetree of Aselloidea reveals species diversification dynamics in groundwater. Systematic

775 Biology, 62(4), 512-522. https://doi.org/10.1093/sysbio/syt015

776

777 Murphy, J., \& Riley, A. J. (1958). A single-solution method for the determination of soluble

778 phosphate in sea water. Journal of the Marine Biological Association of the United Kingdom,

779 37(1), 9-14. https://doi.org/10.1017/S0025315400014776

780 
781 Ni, Z., Wang, S., \& Wang, Y. (2016). Characteristics of bioavailable organic phosphorus in

782 sediment and its contribution to lake eutrophication in China. Environmental pollution, 219, 537-

783 544. https://doi.org/10.1016/j.envpol.2016.05.087

784

785 Oates, J. F., Waterman, P. G., \& Choo, G. M. (1980). Food selection by the south Indian leaf-

786 monkey, Presbytis johnii, in relation to leaf chemistry. Oecologia, 45(1), 45-56.

787 https://doi.org/10.1007/BF00346706

788

789 Paradis, E., Claude, J., \& Strimmer, K. (2004). APE: analyses of phylogenetics and evolution in R 790 language. Bioinformatics, 20(2), 289-290. https://doi.org/10.1093/bioinformatics/btg412

791

792 Parnell, A. C., Inger, R., Bearhop, S., \& Jackson, A. L. (2010). Source partitioning using stable

793 isotopes: coping with too much variation. PloS one, 5(3), e9672.

794 https://doi.org/10.1371/journal.pone.0009672

795

796 Peterson, W. T., \& Ausubel, S. J. (1984). Diets and selective feeding by larvae of Atlantic

797 mackerel Scomber scombrus on zooplankton. Marine ecology progress series. Oldendorf, 17(1), 798 65-75.

799

800 Peterson, B. J., \& Fry, B. (1987). Stable isotopes in ecosystem studies. Annual review of ecology 801 and systematics, 18(1), 293-320. https://doi.org/10.1146/annurev.es.18.110187.001453 802 
803 Phillips, D. L., Inger, R., Bearhop, S., Jackson, A. L., Moore, J. W., Parnell, A. C., ... \& Ward, E.

804 J. (2014). Best practices for use of stable isotope mixing models in food-web studies. Canadian 805 Journal of Zoology, 92(10), 823-835. https://doi.org/10.1139/cjz-2014-0127

806

807 Pienaar, J., Ilany, A., Geffen, E., \& Yom-Tov, Y. (2013). Macroevolution of life-history traits in 808 passerine birds: adaptation and phylogenetic inertia. Ecology Letters, 16(5), 571-576.

809 https://doi.org/10.1111/ele.12077

810

811 Poisot, T., Bever, J. D., Nemri, A., Thrall, P. H., \& Hochberg, M. E. (2011). A conceptual

812 framework for the evolution of ecological specialisation. Ecology letters, 14(9), 841-851.

813 https://doi.org/10.1111/j.1461-0248.2011.01645.x

814

815 Post, D. M. (2002). Using stable isotopes to estimate trophic position: models, methods, and

816 assumptions. Ecology, 83(3), 703-718. https://doi.org/10.1890/0012-

817 9658(2002)083[0703:USITET]2.0.CO;2

818

819 Poulson, T. L., \& Lavoie, K. H. (2000). The trophic basis of subsurface ecosystems. Chapter 12 in

820 'Ecosystems of the World. Vol. 30. Subterranean Ecosystems'.(Eds. H. Wilkens, DC Culver and

821 WF Humphreys.) pp. 231-249.

822

823 R Development Core Team. R: A language and environment for statistical computing. Vienna,

824 Austria; 2016.

825 
826 Revell, L. J. (2012). phytools: an R package for phylogenetic comparative biology (and other

827 things). Methods in Ecology and Evolution, 3(2), 217-223. https://doi.org/10.1111/j.2041-

$828 \quad \underline{210 X .2011 .00169 . x}$

829

830 Rossi, L., \& Fano, A. E. (1979). Role of fungi in the trophic niche of the congeneric detritivorous

831 Asellus aquaticus and A. coxalis (Isopoda). Oikos, 380-385. https://doi.org/10.2307/3544749

832

833 Simon, K. S., Benfield, E. F., \& Macko, S. A. (2003). Food web structure and the role of epilithic

834 biofilms in cave streams. Ecology, 84(9), 2395-2406. https://doi.org/10.1890/02-334

835

836 Smith, E. P. (1982). Niche breadth, resource availability, and inference. Ecology, 63(6), 1675-

837 1681. https://doi.org/10.2307/1940109

838

839 Sperfeld, E., Wagner, N. D., Halvorson, H. M., Malishev, M., \& Raubenheimer, D. (2017).

840 Bridging ecological stoichiometry and nutritional geometry with homeostasis concepts and

841 integrative models of organism nutrition. Functional Ecology, 31(2), 286-296.

842 https://doi.org/10.1111/1365-2435.12707

843

844 Srivastava, D. S., \& Lawton, J. H. (1998). Why more productive sites have more species: an

845 experimental test of theory using tree-hole communities. The American Naturalist, 152(4), 510-

846 529. https://doi.org/10.1086/286187

847

848 Sterner, R. W., \& Elser, J. J. (2002). Ecological stoichiometry: the biology of elements from

849 molecules to the biosphere. Princeton university press. 
851 Thompson, I. D., \& Colgan, P. W. (1990). Prey choice by marten during a decline in prey

852 abundance. Oecologia, 83(4), 443-451. https://doi.org/10.1007/BF00317193

853

854 Thompson, R. M., \& Townsend, C. R. (2005). Energy availability, spatial heterogeneity and

855 ecosystem size predict food-web structure in streams. Oikos, 108(1), 137-148.

856 https://doi.org/10.1111/j.0030-1299.2005.11600.x

857

858 Tinker, M. T., Bentall, G., \& Estes, J. A. (2008). Food limitation leads to behavioral

859 diversification and dietary specialization in sea otters. Proceedings of the national Academy of

860 Sciences, 105(2), 560-565. https://doi.org/10.1073/pnas.0709263105

861

862 Traugott, M., Kamenova, S., Ruess, L., Seeber, J., \& Plantegenest, M. (2013). Empirically

863 characterising trophic networks: what emerging DNA-based methods, stable isotope and fatty

864 acid analyses can offer. In Advances in ecological research (Vol. 49, pp. 177-224). Academic

865 Press. https://doi.org/10.1016/B978-0-12-420002-9.00003-2

866

867 Trumble, S. J., Barboza, P. S., \& Castellini, M. A. (2003). Digestive constraints on an aquatic

868 carnivore: effects of feeding frequency and prey composition on harbor seals. Journal of

869 Comparative Physiology B, 173(6), 501-509. https://doi.org/10.1007/s00360-003-0358-4

870

871 Vanderklift, M. A., \& Ponsard, S. (2003). Sources of variation in consumer-diet $\delta 15 \mathrm{~N}$

872 enrichment: a meta-analysis. Oecologia, 136(2), 169-182. https://doi.org/10.1007/s00442-003-

$873 \quad 1270-\mathrm{z}$ 
875 Zanden, M. J. V., \& Rasmussen, J. B. (2001). Variation in $\delta 15 \mathrm{~N}$ and $\delta 13 \mathrm{C}$ trophic fractionation:

876 implications for aquatic food web studies. Limnology and oceanography, 46(8), 2061-2066.

877 https://doi.org/10.4319/lo.2001.46.8.2061

878

879 Venarsky, M. P., Benstead, J. P., \& Huryn, A. D. (2012). Effects of organic matter and season on

880 leaf litter colonisation and breakdown in cave streams. Freshwater Biology, 57(4), 773-786.

881 https://doi.org/10.1111/j.1365-2427.2012.02742.x

882

883 Venarsky, M. P., Huntsman, B. M., Huryn, A. D., Benstead, J. P., \& Kuhajda, B. R. (2014).

884 Quantitative food web analysis supports the energy-limitation hypothesis in cave stream

885 ecosystems. Oecologia, 176(3), 859-869. https://doi.org/10.1007/s00442-014-3042-3

886

887 Wagner, N. D., Hillebrand, H., Wacker, A., \& Frost, P. C. (2013). Nutritional indicators and their 888 uses in ecology. Ecology letters, 16(4), 535-544. https://doi.org/10.1111/ele.12067

889

890 Warton, D. I., \& Hui, F. K. (2011). The arcsine is asinine: the analysis of proportions in ecology.

891 Ecology, 92(1), 3-10. https://doi.org/10.1890/10-0340.1

892

893 Whitfield, D. P., Reid, R., Haworth, P. F., Madders, M., Marquiss, M., Tingay, R., \& Fielding, A.

894 H. (2009). Diet specificity is not associated with increased reproductive performance of Golden

895 Eagles Aquila chrysaetos in Western Scotland. Ibis, 151(2), 255-264.

896 https://doi.org/10.1111/j.1474-919X.2009.00924.X

897 
898 Yang, Z. (2007). PAML 4: phylogenetic analysis by maximum likelihood. Molecular biology and 899 evolution, 24(8), 1586-1591. https://doi.org/10.1093/molbev/msm088

900

901 Zandona, E., Auer, S. K., Kilham, S. S., Howard, J. L., López-Sepulcre, A., O’Connor, M. P., ... \& 902 Reznick, D. N. (2011). Diet quality and prey selectivity correlate with life histories and predation 903 regime in Trinidadian guppies. Functional Ecology, 25(5), 964-973.

904 https://doi.org/10.1111/j.1365-2435.2011.01865.x

905

906 Zuur, A. F., Ieno, E. N., \& Elphick, C. S. (2010). A protocol for data exploration to avoid common 907 statistical problems. Methods in ecology and evolution, 1(1), 3-14. https://doi.org/10.1111/j.2041-

$908 \quad \underline{210 X .2009 .00001 . X}$

909

910

\section{SUPPORTING INFORMATION}

912 Additional supporting information may be found in the online version of this article.

913 Figure S1: Isoplots (carbon and nitrogen stable isotope compositions of trophic resources and

914 individuals) for the 15 isopod species.

915 Methods S1: Calculation of the selectivity indices of Hurlbert and Smith.

916 Note S1: Discussion of the isotopic analyses (for P. coiffaiti).

917 Table S1: Environmental variables and indices of trophic selectivity.

918 Table S2: Environment characterization: abundance and elemental composition of available 919 trophic resources. 
920 Table S3: Diet determination: median and 95\% credibility interval of resource contributions to the 921 diet.

922 Table S4: Procedure of model selection with RDQual ${ }_{\mathrm{C}: \mathrm{P}}$ (Resource Diversity in terms of Quality, 923 based on C:P ratios).

924 Please note: Wiley Blackwell are not responsible for the content or functionality of any

925 supporting information supplied by the authors. Any queries (other than missing material)

926 should be directed to the corresponding author for the article. 
Figure 2

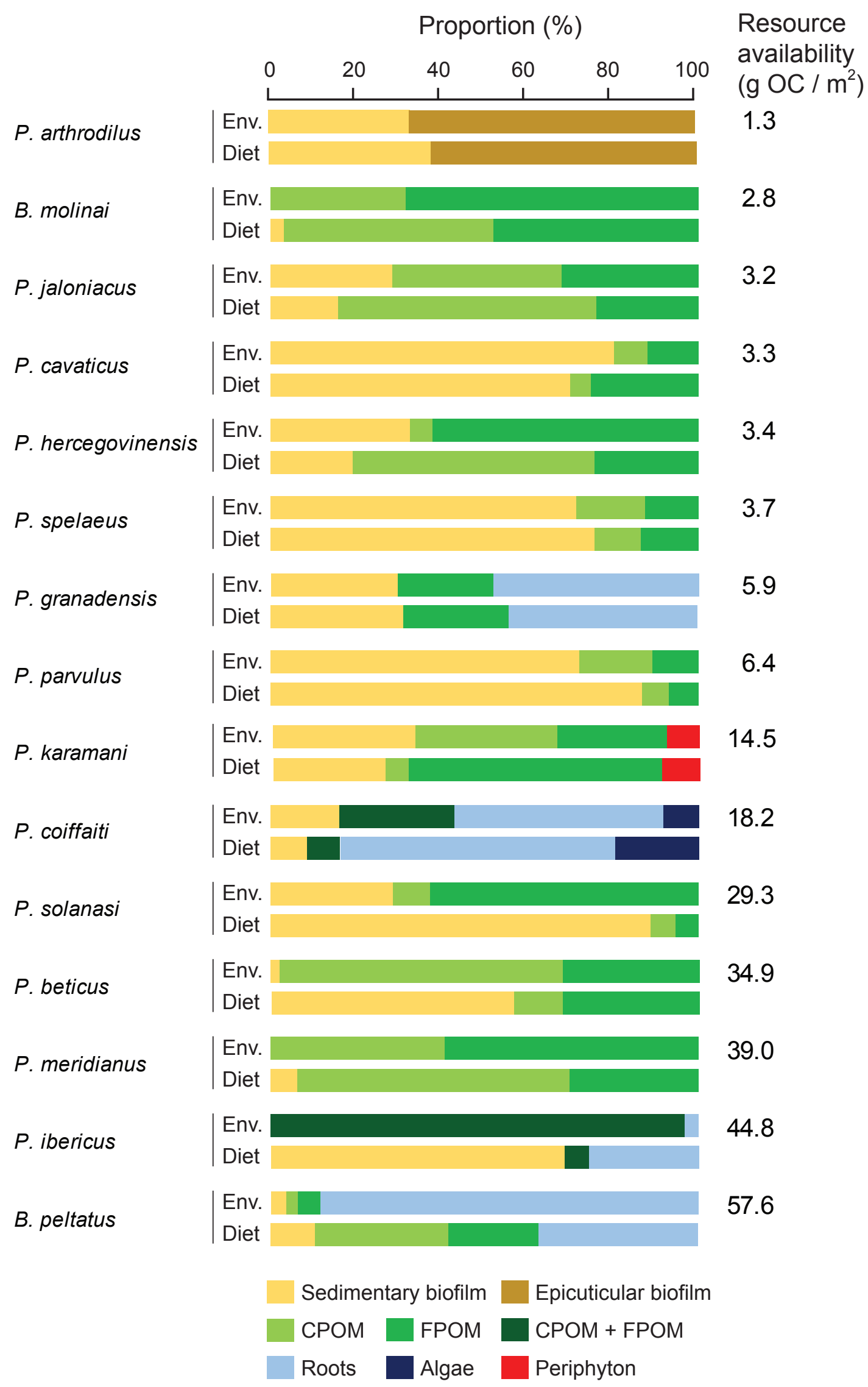




\begin{tabular}{|c|c|c|c|c|c|c|c|c|c|}
\hline Species & & Site & Habitat & $\mathrm{C}: \mathrm{N}_{\text {org }}$ & $\mathrm{C}: \mathrm{P}_{\text {org }}$ & Locality & $\mathrm{CO}$ & LA & LO \\
\hline Proasellus arthrodilus & (Braga, 1945) & 1 & cave stream & 8.86 & 158.9 & Rabacal & PT & 40.03 & -8.47 \\
\hline Bragasellus molinai & (Henry \& Magniez, 1988) & 2 & cave pool & 9.18 & 152.1 & Vegacervera & ES & 42.91 & -5.56 \\
\hline Proasellus jaloniacus & (Henry \& Magniez, 1978) & 3 & hyporheic zone & 5.06 & 101.5 & Benichembla & ES & 38.76 & -0.10 \\
\hline Proasellus cavaticus & (Leydig, 1871) & 4 & cave stream & 5.41 & 105.3 & Thoiria & FR & 46.53 & 5.73 \\
\hline Proasellus hercegovinensis & (Karaman, 1933) & 5 & cave pool & 5.74 & 94.1 & Zavala & BA & 42.85 & 17.98 \\
\hline Proasellus spelaeus & (Racovitza, 1922) & 6 & cave stream & 4.86 & 97.8 & Ancille & FR & 43.14 & -1.20 \\
\hline Proasellus granadensis & (Henry \& Magniez, 2003) & 7 & spring & 4.43 & 64.8 & Alhama de Granada & ES & 37.05 & -4.06 \\
\hline Proasellus parvulus & (Sket, 1960) & 8 & cave stream & 4.57 & 75.6 & Crnomelj & SI & 45.60 & 15.17 \\
\hline Proasellus karamani & (Remy, 1934) & 9 & surface stream & 5.45 & 88.0 & Kljuc & $\mathrm{BA}$ & 43.09 & 18.49 \\
\hline Proasellus coiffaiti & (Henry \& Magniez, 1972) & 10 & surface stream & 5.41 & 108.0 & Cauneille & FR & 43.54 & 1.04 \\
\hline Proasellus solanasi & (Henry \& Magniez, 1972) & 11 & cave entrance & 5.89 & 80.9 & Benajoan & ES & 36.73 & -5.24 \\
\hline Proasellus beticus & (Henry \& Magniez, 1992) & 12 & sinkhole & 5.29 & 108.5 & Vallada & ES & 38.88 & -0.69 \\
\hline Proasellus meridianus & (Racovitza, 1919) & 13 & surface stream & 4.97 & 78.6 & Alfoz de Lloredo & ES & 43.35 & -4.18 \\
\hline Proasellus ibericus & (Braga, 1946) & 14 & surface stream & 5.97 & 76.8 & Ponte de Lima & PT & 41.85 & -8.57 \\
\hline Bragasellus peltatus & (Braga, 1944) & 15 & surface stream & 5.65 & 102.0 & Lousada & PT & 41.28 & -8.31 \\
\hline
\end{tabular}

Table 1: Description of the 15 isopod species.

Species are sorted by increasing resource availability in their environment. C: $\mathrm{N}_{\text {org }}$ and C: $\mathrm{P}_{\text {org }}$ refers respectively to the molar carbon-to-nitrogen and carbon-to-phosphorus ratios of isopods (whole organism). CO stands for the ISO country code and LA / LO stand for the latitude / longitude (in decimal degrees) of the sampling site location. 


\begin{tabular}{lcc} 
& Minimum & Maximum \\
\hline Proportion of resources in the environment (\%) & & \\
Fine particulate organic matter (FPOM) & 0 & 68 \\
Coarse particulate organic matter (CPOM) & 0 & 66 \\
Sedimentary biofilm & 0 & 80 \\
Epicuticular biofilm* & 0 & 67 \\
Periphyton* & 0 & 7 \\
Algae * & 0 & 8 \\
Roots & 0 & 88 \\
\hline Proportion of resources in isopod diet (\%) & & \\
Fine particulate organic matter (FPOM) & 5 & 57 \\
Coarse particulate organic matter (CPOM) & 5 & 63 \\
Sedimentary biofilm & 3 & 87 \\
Epicuticular biofilm * & - & 62 \\
Periphyton* & - & 8 \\
Algae * & - & 19 \\
Roots & 25 & 64 \\
\hline
\end{tabular}

Table 2: Overview of the range of resources abundance and use across the 15 sampling sites.

This table presents the minimum and maximum abundances of each trophic resource across the 15 surveyed environments (as \% of the total OC $/ \mathrm{m}^{2}$ ).

The minimum and maximum proportions of each resource in the diet of isopods are presented in

the same way (considering only the sites where the given resource was available).

* denotes the 3 resources present in only one of the 15 sampling sites. 


\begin{tabular}{|c|c|c|}
\hline PGLS models & AICc & adjusted $R^{2}$ \\
\hline $\mathrm{PS}^{\prime} \sim \mathrm{RA} * \mathrm{RDQuant}^{*} \mathrm{RDQual}_{\mathrm{C}: \mathrm{N}}$ & 73.71 & 0.47 \\
\hline $\mathrm{PS}^{\prime} \sim \mathrm{RDQuant}^{*} \mathrm{RDQual}_{\mathrm{C}: \mathrm{N}}$ & 65.19 & -0.24 \\
\hline $\mathrm{PS}^{\prime} \sim$ RDQuant + RDQual ${ }_{\mathrm{C}: \mathrm{N}}$ & 61.49 & -0.15 \\
\hline PS' RDQuant & 58.52 & -0.08 \\
\hline $\mathrm{PS}^{\prime} \sim \mathrm{RDQual}_{\mathrm{C}: \mathrm{N}}$ & 58.31 & -0.06 \\
\hline $\mathrm{PS}^{\prime} \sim \mathrm{RA}+\mathrm{RDQuant}^{+} \mathrm{RDQual}_{\mathrm{C}: \mathrm{N}}$ & 54.90 & 0.37 \\
\hline PS' RA * RDQuant & 54.76 & 0.38 \\
\hline $\mathrm{PS}^{\prime} \sim \mathrm{RA} * \mathrm{RDQual}_{\mathrm{C}: \mathrm{N}}$ & 54.10 & 0.41 \\
\hline PS' RA + RDQuant & 51.21 & 0.42 \\
\hline $\mathrm{PS}^{\prime} \sim \mathrm{RA}+\mathrm{RDQual}_{\mathrm{C:N}}$ & 51.20 & 0.42 \\
\hline $\mathbf{P S}^{\prime} \sim$ RA & 48.10 & 0.46 \\
\hline
\end{tabular}

Table 3 : Procedure of model selection.

Models are ranked by decreasing Akaike's information criterion corrected for small sample size (AICc). A difference of AICc between two models is considered as a significant improvement in favour of the model with the lowest AICc (Burnham \& Anderson, 2002). PS', RA, RDQual ${ }_{\mathrm{C}: \mathrm{N}}$ and

RDQuant represent the trophic selectivity, the Resource Availability (as g of OC / $\mathrm{m}^{2}$ ), the Resource Diversity in terms of Quality (based on C:N ratios), and in terms of Quantity, respectively (see main text for details). The 'adjusted $\mathrm{R}^{21}$ (modified $\mathrm{R}^{2}$ that has been adjusted for the number of predictors in the model) is indicated here as an estimation of the proportion of variance explained by the corresponding model. 